\title{
BMJ
}

\section{Nutritional intervention in patients with type 2 diabetes who are hyperglycaemic despite optimised drug treatment- Lifestyle Over and Above Drugs in Diabetes (LOADD) study: randomised controlled trial}

\author{
Kirsten J Coppell, senior research fellow, ${ }^{1}$ Minako Kataoka, research dietitian, ${ }^{2}$ Sheila M Williams, research \\ associate professor, ${ }^{3}$ Alex W Chisholm, senior lecturer nutrition, ${ }^{2}$ Sue M Vorgers, research nurse, ${ }^{2}$ Jim I Mann, \\ professor of human nutrition and medicine
}

\begin{abstract}
${ }^{1}$ Edgar National Centre for Diabetes and Obesity Research, Department of Medical and Surgical Sciences, University of Otago, PO Box 913, Dunedin 9054, New Zealand

${ }^{2}$ Department of Human Nutrition, University of Otago

${ }^{3}$ Department of Preventive and Social Medicine, University of Otago

Correspondence to: $\mathrm{K}$ Coppell
\end{abstract} kirsten.coppell@otago.ac.nz

Cite this as: BMJ 2010;341:C3337 doi:10.1136/bmj.c3337

\section{ABSTRACT}

Objective To determine the extent to which intensive dietary intervention can influence glycaemic control and risk factors for cardiovascular disease in patients with type 2 diabetes who are hyperglycaemic despite optimised drug treatment.

Design Randomised controlled trial.

Setting Dunedin, New Zealand.

Participants 93 participants aged less than 70 years with type 2 diabetes and a glycated haemoglobin $\left(\mathrm{HbA}_{1} \mathrm{c}\right.$ of more than $7 \%$ despite optimised drug treatments plus at least two of overweight or obesity, hypertension, and dyslipidaemia.

Intervention Intensive individualised dietary advice (according to the nutritional recommendations of the European Association for the Study of Diabetes) for six months; both the intervention and control participants continued with their usual medical surveillance.

Main outcome measures $\mathrm{HbA}_{1 \mathrm{c}}$ was the primary outcome. Secondary outcomes included measures of adiposity, blood pressure, and lipid profile.

Results After adjustment for age, sex, and baseline measurements, the difference in $\mathrm{HbA}_{1 \mathrm{c}}$ between the intervention and control groups at six months $(-0.4 \%$, $95 \%$ confidence interval $-0.7 \%$ to $-0.1 \%$ ) was highly statistically significant $(P=0.007)$, as were the decreases in weight $(-1.3 \mathrm{~kg},-2.4$ to $-0.1 \mathrm{~kg} ; \mathrm{P}=0.032)$, body mass index $(-0.5,-0.9$ to $-0.1 ; \mathrm{P}=0.026)$, and waist circumference $(-1.6 \mathrm{~cm},-2.7$ to $-0.5 \mathrm{~cm} ; \mathrm{P}=0.005)$. A decrease in saturated fat $(-1.9 \%$ total energy, $-3.3 \%$ to $-0.6 \% ; \mathrm{P}=0.006)$ and an increase in protein $(1.6 \%$ total energy, $0.04 \%$ to $3.1 \%$; $P=0.045$ ) in the intervention group were the most striking differences in nutritional intake between the two groups.

Conclusions Intensive dietary advice has the potential to appreciably improve glycaemic control and anthropometric measures in patients with type 2 diabetes and unsatisfactory $\mathrm{HbA}_{1 \mathrm{c}}$ despite optimised hypoglycaemic drug treatment.

Trial registration Clinical trials NCT00124553.

\section{INTRODUCTION}

Lifestyle modification, in particular recommendations to follow an appropriate dietary pattern, has generally been accepted as a cornerstone of treatment for people with type 2 diabetes, with the expectation that an appropriate intake of energy and nutrients will improve glycaemic control and reduce the risk of complications. ${ }^{1}$ However, adherence to healthy lifestyle changes is difficult for many people, and taking tablets is often an easier option. ${ }^{2}$

Before the introduction of oral hypoglycaemic agents, diet and, for a few, insulin were the only available treatments. During the 1970s the types of diets prescribed and the degree of adherence varied widely. ${ }^{3}$ Despite many short term studies providing compelling evidence of the potential for various dietary modifications to improve glycaemic control and risk factors for cardiovascular disease, ${ }^{1}$ the appearance of new oral hypoglycaemic agents, the increased use of insulin in type 2 diabetes, and the frequent prescription of statins and antihypertensive agents may have resulted in further reliance on pharmacological rather than nutritional treatment. ${ }^{4-7}$ In parallel with increased prescription of cardioprotective drugs, reductions in blood pressure and in total cholesterol and low density lipoprotein cholesterol have been seen in people with type 2 diabetes. ${ }^{689}$ Measures of adiposity and glycaemic control have deteriorated over the same period, however. ${ }^{6}$ The observation of an inexorable deterioration in glycaemic control regardless of the nature of hypoglycaemic drug treatment during the United Kingdom Prospective Diabetes Study (UKPDS), ${ }^{10}$ and the reluctance among some patients to sufficiently alter lifestyle practices, ${ }^{11}{ }^{12}$ may further explain a preference for drugs over dietary advice. The potential of dipeptidyl-peptidase IV inhibitors, a costly new pharmacological approach, to produce modest reductions in glycated haemoglobin $\left(\mathrm{HbA}_{1 \mathrm{c}}\right)$ in patients with type 2 diabetes on maximum doses of conventional treatments seems likely to perpetuate this trend. ${ }^{13}$ 
Moreover, the addition of insulin for patients on maximally tolerated sulphonylureas and metformin has the potential for additional weight gain and increased risk of hypoglycaemic episodes. ${ }^{14}$

The major studies that showed the benefits of diet treatment were carried out before the recommendations that led to the greatly increased prescription of hypoglycaemic and cardioprotective drugs and were of short duration. ${ }^{15-19}$ The Lifestyle Over and Above Drugs in Diabetes (LOADD) study therefore investigated the extent to which intensive evidence based dietary advice is able to influence glycaemic control and risk factors for cardiovascular disease in people with type 2 diabetes who had persistent hyperglycaemia and remained at high cardiovascular risk despite their drug treatment having been optimised according to current guidelines.

\section{METHODS}

The LOADD study, a randomised controlled trial of six months' duration, took place at the Department of Human Nutrition, University of Otago, Dunedin, New Zealand, between October 2006 and July 2009.

\section{Participants}

We recruited potential participants through local general practices, hospital diabetes clinics, the regional diabetes retinal screening service, pharmacies, and the local diabetes society and through advertising in the local weekly newspaper. We required them to be under 70 years of age, be resident within the Dunedin city boundary, have been diagnosed with type 2 diabetes more than nine months before study entry, and, despite having been given standard dietary advice by dietitian, doctor, or nurse and prescribed oral hypoglycaemic agents, insulin, or both, have persistent unsatisfactory glycaemic control defined as $\mathrm{HbA}_{1 \mathrm{c}}$ more than $7 \%$. As the study was aimed at people at high risk of cardiovascular disease, we also required participants to have at least two of the following three characteristics: overweight or obesity (body mass index $\geq 25$ ), hypertension (currently prescribed antihypertensive drugs or blood pressure $>140 / 90 \mathrm{~mm} \mathrm{Hg}$ despite optimised antihypertensive drug treatment), and dyslipidaemia (currently prescribed lipid modifying drugs or one or more of total cholesterol $>5.2 \mathrm{mmol} / \mathrm{l}$, low density lipoprotein cholesterol $>3.5 \mathrm{mmol} / \mathrm{l}$, triglycerides $>2.0 \mathrm{mmol} / \mathrm{l}$, and high density lipoprotein cholesterol $<1.0 \mathrm{mmol} / \mathrm{l}$ despite optimised lipid modifying drug treatment). Pregnancy, the presence of a serious chronic illness other than diabetes considered likely to need a start or change of drug treatment during the trial, or unwillingness to attempt to comply with intensive dietary advice if randomised to the intervention group excluded participation.

Potential participants were screened by telephone by a research nurse or research dietitian and then by a medical officer during a clinical assessment that included a blood test for measurements of $\mathrm{HbA}_{1 \mathrm{c}}$ and fasting lipids. We considered participants suitable for randomisation to the intervention or control group if they fulfilled the entry criteria and were receiving appropriate maximally tolerated classes and doses of drug treatments for blood glucose, blood pressure, and lipid control according to national and international guidelines for the management of type 2 diabetes. ${ }^{17-19}$ Those who fulfilled the entry criteria but were not being treated with appropriate drugs or in whom dosage adjustment was needed were recommended an optimised treatment regimen. We reassessed their eligibility for randomisation after stabilisation on their new treatment regimen, requiring that appropriate drug treatment had been started and adjusted according to guidelines. All clinical assessments and adjustments of treatment were carried out under the supervision of one of the authors (JM), who has more than 30 years of experience as a consultant physician with expertise in diabetes and an involvement in developing guidelines nationally and internationally. All randomised participants were thus considered not to be well controlled despite receiving optimised drug treatments.

\section{Randomisation}

Two research assistants not involved with the study did the randomisation in blocks of 10 by using sealed opaque envelopes and with stratification according to sex and $\mathrm{HbA}_{1 \mathrm{c}}(7-8 \%$, or $>8 \%)$ measured at the clinical

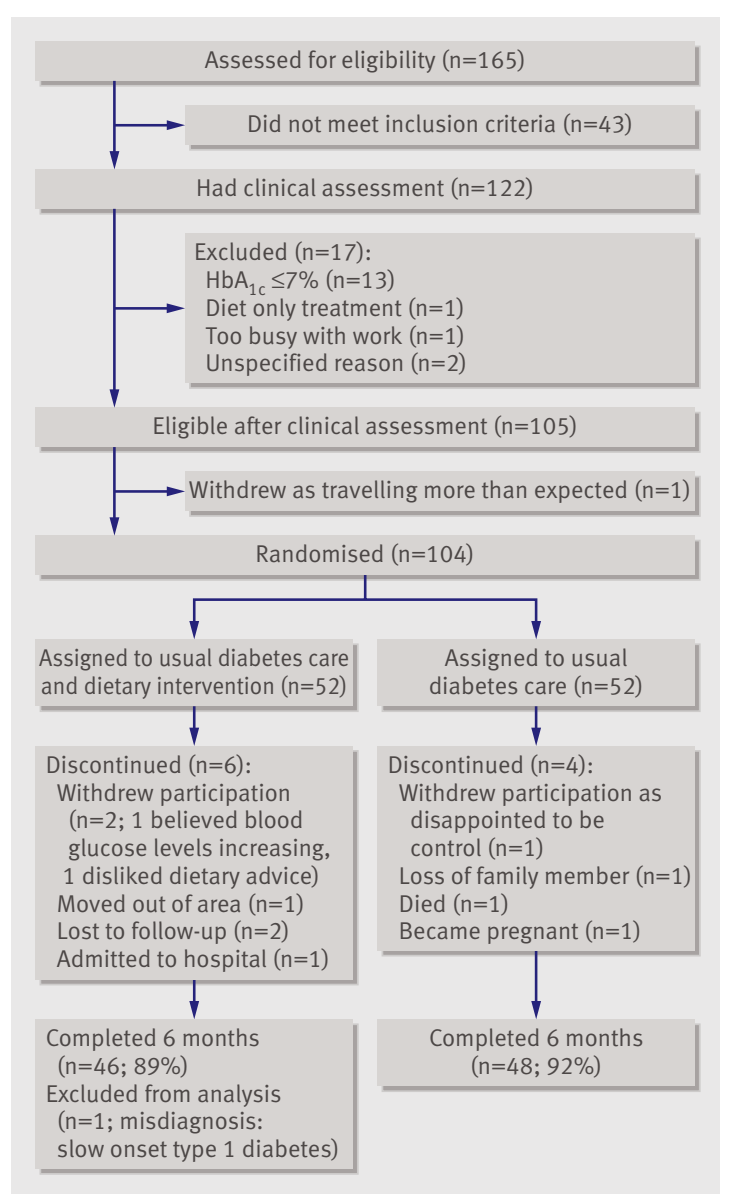

Flow chart of participants. 
Table 1|Baseline characteristics of study participants in intervention and control groups. Values are numbers (percentages) unless stated otherwise

\begin{tabular}{lcc} 
Characteristics & $\begin{array}{c}\text { Intervention } \\
(\mathbf{n = 4 5 )}\end{array}$ & $\begin{array}{c}\text { Control } \\
(\mathrm{n}=48)\end{array}$ \\
$\begin{array}{l}\text { Mean (SD) age (years) } \\
\text { Women }\end{array}$ & $28(6.6)$ & $27(56)$ \\
\hline Self identified ethnicity: & $34(76)$ & $42(88)$ \\
\hline New Zealand European & $1(2)$ & $2(4)$ \\
\hline Māori & $3(7)$ & $0(0)$ \\
\hline Pacific Island & $7(16)$ & $4(8)$ \\
\hline Other & $4(9)$ & $3(6)$ \\
\hline Current smoker & $8.7(6.4)$ & $9.0(5.8)$ \\
\hline Mean (SD) duration of diabetes (years) & & $34(71)$ \\
\hline Drug groups: & $31(69)$ & $0(0)$ \\
\hline Oral hypoglycaemic agents only & $1(2)$ & $14(29)$ \\
\hline Insulin only & $13(29)$ & $31(65)$ \\
\hline Insulin and oral hypoglycaemic agent(s) & $26(58)$ & $30(63)$ \\
\hline Lipid modifying drugs & $24(53)$ & $23(48)$ \\
\hline $\begin{array}{l}\text { Angiotensin converting enzyme inhibitor, } \\
\text { angiotensin II receptor blocker, or both }\end{array}$ & $14(31)$ & $31(65)$ \\
\hline Other antihypertensive agents & $17(38)$ & \\
\hline Aspirin & & \\
\hline
\end{tabular}

assessment or after optimisation of drug treatment. The randomisation took place at a separate site, supervised by the study statistician.

\section{Intervention}

Both groups received one-off "push play" advice on physical activity - that is, on the desirability of achieving at least 30 minutes of physical activity of moderate intensity on most, if not all, days of the week. ${ }^{20}$ Both groups continued to attend their usual provider of clinical care for diabetes (general practitioner or hospital diabetes clinic). Participants in the control group were given an undertaking that they would receive further advice depending on the outcome of the trial, and they had no further contact with the researchers until they and those randomised to receive intensive dietary intervention were reassessed at the end of the six month trial.

The intensive dietary intervention was based on the evidence based recommendations of the Diabetes and Nutrition Study Group of the European Association for the Study of Diabetes. ${ }^{1}$ The recommended distribution of macronutrients was protein $10-20 \%$ of total energy, total fat less than $30 \%$ of total energy, saturated fat less than $10 \%$ of total energy or less than $8 \%$ of total energy if low density lipoprotein cholesterol was raised, polyunsaturated fatty acids less than $10 \%$ of total energy, and carbohydrate $45-60 \%$ of total energy. The target for dietary fibre intake was $40 \mathrm{~g} /$ day-or $20 \mathrm{~g} / 4184 \mathrm{~kJ}(1000 \mathrm{kcal})$-about half of which was intended to be soluble fibre. For participants who were overweight or obese, the recommendation was to achieve modest (at least 5\%) weight loss. We translated recommended total energy intake and nutrient distribution for each participant into foods, recipes, and meals on the basis of the initial three day weighed diet record, personal preference, budget, and sociocultural factors. The emphasis was on appropriate food quantities, vegetables, fruit, legumes, wholegrain cereals, fish (preferably oily), nuts, low fat dairy products, and appropriate fats and oils. Meat, when consumed, was to be lean.

Each participant had two individual sessions with the study dietitian within the first month after randomisation, then monthly sessions for five months. One group education session within the first two months and a telephone call between visits, as deemed necessary by the dietitian, provided opportunities to reinforce the dietary advice and give additional support. Participants' family members were encouraged to attend dietary education sessions. Clinical measurements (anthropometric measures and blood pressure) and blood tests $\left(\mathrm{HbA}_{1 \mathrm{c}}\right.$ and lipids) at three months were an integral component of the six month intervention and provided a means of offering feedback on progress and further support.

\section{Study outcomes}

The primary outcome measure was $\mathrm{HbA}_{1 \mathrm{c}}$. Secondary outcome measures included changes in hypoglycaemic drugs (type and dose), weight, body mass index, waist circumference, blood pressure, fasting plasma glucose, and lipid profile.

Measurements were made at baseline and six months. We recorded demographic data at baseline, a nurse administered a questionnaire on medical history, drugs, and physical activity, and a dietitian gave instruction on completion of a three day weighed diet record (two weekdays and one weekend day) at baseline and six months. Trained research nurses made resting blood pressure (triplicate) and anthropometric (duplicate) measurements under standardised conditions and took blood samples after a 10 hour overnight fast. These measurements were made on two separate occasions (within one week) and averaged. Blood samples were analysed at the Lipid and Diabetes Laboratory of the Department of Human Nutrition, University of Otago, using methods previously described by our laboratory. ${ }^{21}$ Southern Community Laboratory Dunedin analysed urine samples. Urinary creatinine was measured on a Roche Hitachi 911 analyser using the Jaffé reaction method. Urinary albumin was assayed on a Roche Modular analyser using the Tinaquant immuno-turbidmetric assay.

\section{Statistical analysis}

We based an estimate of the sample size for the study on data from the Otago diabetes register. ${ }^{22}$ Calculations used a standard deviation of $1.4 \%$ and a correlation between measures of 0.8 . We needed to enrol at least 41 people in each treatment group to detect a difference of $0.57 \%$ in $\mathrm{HbA}_{1 \mathrm{c}}$ with $80 \%$ power at the $5 \%$ level of significance allowing for a $10 \%$ dropout rate. ${ }^{23}$ We analysed the data in accordance with a modified intention to treat principle, using a pre-established analysis plan. We used analysis of covariance, with adjustment for sex, age, and the baseline measure, to 
Table 2|Primary and secondary end points at baseline and six months and adjusted differences between intervention and control groups. Values are means (SD) unless stated otherwise

\begin{tabular}{|c|c|c|c|c|c|c|}
\hline \multirow[b]{2}{*}{ Measures } & \multicolumn{2}{|c|}{ Intervention $(n=45)$} & \multicolumn{2}{|c|}{ Control $(n=48)$} & \multirow[b]{2}{*}{ 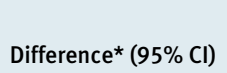 } & \multirow[b]{2}{*}{$P$ value* } \\
\hline & Baseline & 6 months & Baseline & 6 months & & \\
\hline $\mathrm{HbA}_{1 \mathrm{c}}(\%)$ & $8.9(1.4)$ & $8.4(1.0)$ & $8.6(1.3)$ & $8.6(1.2)$ & $-0.4(-0.7$ to -0.1$)$ & 0.007 \\
\hline Glucose (mmol/l) & $9.0(2.6)$ & $8.1(2.2)$ & $8.3(2.4)$ & $8.3(2.9)$ & $-0.6(-1.5$ to 0.3$)$ & 0.181 \\
\hline Weight (kg) & $98.4(18.7)$ & $96.3(18.0)$ & $95.1(18.8)$ & $94.5(18.3)$ & $-1.3(-2.4$ to -0.1$)$ & 0.032 \\
\hline Body mass indext & $35.1(6.1)$ & $34.3(5.8)$ & $34.2(6.0)$ & $34.0(5.9)$ & $-0.5(-0.9$ to -0.1$)$ & 0.026 \\
\hline Waist circumference (cm) & $111.4(13.7)$ & $108.9(13.6)$ & $108.0(12.8)$ & $107.4(12.7)$ & $-1.6(-2.7$ to -0.5$)$ & 0.005 \\
\hline Systolic blood pressure (mm Hg) & $131.9(15.8)$ & $127.8(15.6)$ & $131.7(16.1)$ & $129.2(16.4)$ & $-1.4(-6.1$ to 3.2$)$ & 0.536 \\
\hline Diastolic blood pressure (mm Hg) & $79.8(9.0)$ & $76.5(8.7)$ & $79.0(10.3)$ & $76.4(10.6)$ & $-0.5(-3.0$ to 2.0$)$ & 0.673 \\
\hline Total cholesterol (mmol/l) & $4.35(0.93)$ & $4.11(0.97)$ & $3.93(0.84)$ & $3.87(0.94)$ & $-0.14(-0.38$ to 0.10$)$ & 0.248 \\
\hline HDL cholesterol (mmol/l) & $1.04(0.22)$ & $1.04(0.25)$ & $1.03(0.22)$ & $1.01(0.24)$ & $0.01(-0.04$ to 0.05$)$ & 0.747 \\
\hline LDL cholesterol (mmol/l) & $2.52(0.83)$ & $2.30(0.82)$ & $2.16(0.71)$ & $2.13(0.80)$ & $-0.15(-0.35$ to 0.06$)$ & 0.162 \\
\hline Triglycerides (mmol/l) & $1.71(0.83)$ & $1.67(1.04)$ & $1.61(0.65)$ & $1.59(0.68)$ & $0.01(-0.26$ to 0.28$)$ & 0.933 \\
\hline Uric acid $(\mu \mathrm{mol} / \mathrm{l})$ & $302.1(78.9)$ & $313.3(81.5)$ & $316.2(74.0)$ & $315.9(79.5)$ & $11.0(-3.7$ to 25.6$)$ & 0.140 \\
\hline Urine albumin:creatinine ratioł & $7.5(24.6)$ & $7.1(23.8)$ & $11.0(53.1)$ & $5.6(22.2)$ & $3.4(-0.5$ to 7.4$)$ & 0.089 \\
\hline
\end{tabular}

$\mathrm{HDL}=$ high density lipoprotein; LDL=low density lipoprotein.

*Adjusted for age, sex, and baseline measurements.

†Calculated as weight in kilograms divided by square of height in metres.

$\ddagger$ Complete urine samples not obtained for two participants in intervention group and one participant in control group; albumin was measured in

milligrams per litre, and creatinine was measured in grams per litre; urine albumin:creatinine ratio values were log transformed.

compare the differences between the treatments at six months. We used two sided significance tests throughout. The results are presented as differences (with $95 \%$ confidence intervals) between the two groups. We made no adjustment for multiple testing.

\section{RESULTS}

Figure 1 shows the flow of participants through the study. Of 104 eligible participants randomised, 94 $(90 \%)$ completed the six month study. Table 1 provides key characteristics of the two groups. Most participants in both groups described themselves as New Zealanders of European descent. However, the intervention group was ethnically more diverse - one quarter were of Mori, Pacific Island, Lebanese, or Indian ethnicity. Participants in the intervention group were slightly younger, but smoking status, duration of diabetes, and use of hypoglycaemic drugs were similar in the two groups.

Table 2 shows baseline and six month measurements of the primary and secondary end points and the adjusted differences between the two groups. Improvements occurred in most clinical and laboratory measures in the intervention group, and minimal changes occurred in the control group. The difference in $\mathrm{HbA}_{1 \mathrm{c}}$ between the two groups $(0.4 \%)$ at the end of the six month intervention after adjustment for baseline values, age, and sex was highly significant $(\mathrm{P}=0.007)$. Similarly, we saw improvements in anthropometric measures in the intervention group, and differences between the two groups were statistically significant.

Almost a third ( $\mathrm{n}=14 ; 29 \%)$ of the control group had prescribed doses of hypoglycaemic drugs increased during the study period compared with four $(9 \%)$ of the intervention group. Six (13\%) intervention participants and two $(4 \%)$ controls had decreases in the dose of prescribed hypoglycaemic drugs. In the intervention group, four of the 14 patients on insulin had their insulin doses decreased by up to 81 units. No serious adverse events were reported.

Table 3 shows the nutritional intakes calculated for the 78 participants for whom complete three day weighed diet records were available at both baseline and six months. A decrease in saturated fat $(\mathrm{P}=0.006)$ and an increase in dietary protein $(\mathrm{P}=0.045)$ were the most striking differences between the two groups. Analysis of the food groups showed greater consumption of low fat dairy products and nuts in the intervention group. At six months, a higher proportion of total energy consumed by intervention participants compared with control participants was from low fat dairy products ( $8 \% v 6 \%$ total energy) and nuts (5\% v 1\% total energy). In contrast, $7 \%$ of total energy among control participants and 3\% of total energy among intervention participants was from high fat dairy products.

\section{DISCUSSION}

In this study, intensive nutrition treatment achieved an improvement in both glycaemic control and anthropometric measures in patients with type 2 diabetes at high risk of cardiovascular disease whose control was considered to be unsatisfactory despite optimum drug treatment according to international management guidelines. ${ }^{17-19}$ This effect occurred despite the fact that some of the patients considered to be on maximum drug treatment were able to reduce their dose of tablets or insulin. The magnitude of the reduction in $\mathrm{HbA}_{1 \mathrm{c}}(0.4 \%)$ is comparable with that seen in clinical trials when a new drug has been added to conventional agents. $^{24-26}$ For example, the use of vildagliptin together with insulin results in $\mathrm{HbA}_{1 \mathrm{c}}$ reductions of $0.3 \%$ compared with the effects of insulin alone. ${ }^{25}$

The reduction in $\mathrm{HbA}_{1 \mathrm{c}}$ may seem to be modest. However, the relation between $\mathrm{HbA}_{1 \mathrm{c}}$ and 
Table $3 \mid$ Nutrient intakes at baseline and six months and adjusted differences between intervention and control groups at six months. Values are means (SD) unless stated otherwise

\begin{tabular}{|c|c|c|c|c|c|c|}
\hline \multirow[b]{2}{*}{ Nutrients } & \multicolumn{2}{|c|}{ Intervention } & \multicolumn{2}{|c|}{ Control } & \multirow[b]{2}{*}{$\begin{array}{c}\text { Difference* } \\
(95 \% \mathrm{Cl})\end{array}$} & \multirow[b]{2}{*}{ Pvalue* } \\
\hline & $\begin{array}{l}\text { Baseline } \\
(n=39)\end{array}$ & $\begin{array}{c}6 \text { months } \\
(n=39)\end{array}$ & $\begin{array}{l}\text { Baseline } \\
(n=39)\end{array}$ & $\begin{array}{c}6 \text { months } \\
(n=39)\end{array}$ & & \\
\hline Energy (kJ) & 8020 (1899) & $6855(1770)$ & $7845(2085)$ & $7171(2087)$ & $-334(-1082$ to 414$)$ & 0.376 \\
\hline Protein (\% TE) & $19.7(3.7)$ & $22.1(3.9)$ & $19.2(3.5)$ & $20.4(4.1)$ & $1.6(0.04$ to 3.1$)$ & 0.045 \\
\hline Total fat (\% TE) & $30.9(6.1)$ & $28.7(5.3)$ & $29.8(6.1)$ & $29.9(6.6)$ & $-1.7(-4.4$ to 1.0$)$ & 0.211 \\
\hline Saturated fatty acids (\% TE) & $11.2(3.2)$ & $9.7(2.5)$ & $11.3(3.5)$ & $11.7(3.4)$ & $-1.9(-3.3$ to -0.6$)$ & 0.006 \\
\hline Polyunsaturated fatty acids (\% TE) & $5.2(1.6)$ & $5.6(1.8)$ & $5.1(2.0)$ & $4.7(1.9)$ & $1.2(-0.7$ to 3.2$)$ & 0.211 \\
\hline Carbohydrate (\% TE) & $47.5(7.1)$ & $48.0(5.3)$ & $50.1(7.5)$ & $48.5(7.2)$ & $0.5(-2.3$ to 3.2$)$ & 0.731 \\
\hline Dietary fibre (g) & $25.7(6.3)$ & $26.3(7.3)$ & $26.4(5.6)$ & $23.5(7.6)$ & $3.0(-0.2$ to 6.1$)$ & 0.064 \\
\hline
\end{tabular}

TE=total energy.

*Adjusted for age, sex, and baseline measurements.

complications of diabetes is continuous, so that any reduction in $\mathrm{HbA}_{1 \mathrm{c}}$ is likely to reduce the risk of complications. In the UKPDS, in which no threshold for risk was seen, each $1 \%$ reduction in mean $\mathrm{HbA}_{1 \mathrm{c}}$ was associated with reductions in risk of $21 \%$ for any end point. ${ }^{27}$ As expected from other studies in which patients with type 2 diabetes on various drugs have been followed prospectively, participants in the control group showed no improvement in glycaemic control, despite increased doses or changes in their hypoglycaemic drugs. ${ }^{10}$ Measures of adiposity improved in parallel with improvements in $\mathrm{HbA}_{1 \mathrm{c}}$, and the differences between the two groups were also significant. This is in contrast to insulin treatment, of which weight gain is a common side effect. ${ }^{14}$ Failure to show significant differences in blood pressure or in total cholesterol and low density lipoprotein cholesterol between the groups may be due to the fact that values were close to target levels at the start of the study and that current antihypertensive and lipid modifying drugs are effective.

\section{Comparison with other studies}

Nutritional modification has repeatedly been shown to have the potential to improve glycaemic control and reduce cardiovascular risk in both type 1 and type 2 diabetes, ${ }^{151628}$ but no definitive data show its potential in the context of intensive drug treatment as currently recommended. In a small study, Aas and colleagues suggested that intensive lifestyle intervention was as effective as insulin in improving glycaemic control in patients with type 2 diabetes on maximal tolerated doses of oral hypoglycaemic agents, with additional benefit in that lifestyle change was associated with weight loss whereas those randomised to insulin gained weight. ${ }^{29}$ In another small study, Goudswaard and colleagues confirmed in a similar group of patients that an intensive educational programme, including dietary instruction, had the potential to improve glycaemic control to the extent that delaying the introduction of insulin was considered appropriate. ${ }^{30}$ Both the ICAN study and Look AHEAD study also showed benefits from a lifestyle intervention among overweight and obese patients with type 2 diabetes, but in those studies the patients did not necessarily have poor glycaemic control and no attempt was made to optimise drug treatment beforehand ${ }^{2331}$; weight loss, rather than glycaemic control, was the primary outcome. No studies to date have approached the clinical question considered here, which is increasingly relevant as patients with type 2 diabetes are prescribed an increasing number of drugs and, like populations of non-diabetic people worldwide, are becoming increasingly overweight and obese. ${ }^{323}$ Excess adiposity is associated not only with more difficult to control levels of blood glucose and diabetes related complications but also with an increased risk of other serious morbidities and mortality, including an increased risk of several important cancers. ${ }^{34}$

\section{Strengths and limitations of study}

The high retention rate throughout the study is a major strength, as is the fact that the dietary intervention was based on internationally accepted guidelines, those of the Diabetes and Nutrition Study Group of the European Association for the Study of Diabetes. ${ }^{1}$ The non-prescriptive dietary approach, consideration of participants' background and socioeconomic circumstances, and non-reliance on commercially prepared meal replacements may have contributed to the high retention rate. The fact that participants were volunteers who were prepared to make substantial lifestyle changes, as well as the six month duration of the intervention, may be perceived to be weaknesses of the study. However, a high level of motivation and compliance is an essential prerequisite for all therapeutic options in diabetes, and the efficacy of the dietary intervention was the focus, rather than its maintenance. The need to explore various approaches to self management, including the adoption and maintenance of nutritional changes, is widely recognised. ${ }^{35}$

\section{Implications}

The Diabetes and Nutrition Study Group guidelines are less prescriptive than many earlier sets of dietary advice. They acknowledge that several dietary patterns can be adopted as treatments for type 2 diabetes. These relatively new guidelines emphasise that appropriate intakes of total energy and a dietary pattern in which intact fruits, vegetables, wholegrain cereals, and low fat 


\section{WHAT IS ALREADY KNOWN ON THIS TOPIC}

Lifestyle modification, in particular recommendations to follow an appropriate dietary pattern, is the cornerstone of treatment for people with type 2 diabetes, but adherence is often difficult

No evidence of benefit exists for nutritional treatment in patients with type 2 diabetes who are hyperglycaemic on optimised conventional drug treatment

\section{WHAT THIS STUDY ADDS}

Individualised intensive dietary advice has the potential to improve glycaemic control and anthropometric measures in patients with type 2 diabetes and unsatisfactory $\mathrm{HbA}_{1 \mathrm{c}}$ despite optimised hypoglycaemic drug treatment

protein sources predominate are more important than the precise proportions of total energy provided by the major macronutrients. For people who prefer a rather higher intake of fat, a Mediterranean-type diet is perfectly acceptable provided the fat sources are derived from monounsaturated and polyunsaturated oils. The guidelines can thus take cultural practices and personal preferences into account, and a traditional Mediterranean-type diet is as acceptable as a low fat diet rich in minimally processed carbohydrate containing foods. The diversity of options, compatible with the guidelines of the American Diabetes Association, should enhance adherence. ${ }^{36}$

These observations should not be taken in any way as a suggestion that achieving substantial dietary change to the extent that will be associated with demonstrable reduction in risk is an easy task. A specialist health professional, usually a dietitian, is almost always needed to enthuse the patients and to translate the nutritional recommendations into practical advice. However, the extent of the improvement in glycaemic control seen in this trial should encourage patients to modify their eating habits, even though this will for many involve quite substantial change from current practice. This requires not only expert advice but also support from the family and an environment that enables appropriate food choices. ${ }^{37}$

We thank all participants in the LOADD study; general practices, the Dunedin Hospital diabetes clinic and Otago Diabetic Eye Monitoring Service, and Diabetes Otago, who assisted with recruitment; Wendy Aitken, Claire Lamb, Michelle McGrath, Margaret Waldron, and Sharyn Willis for clinical and dietetic assistance; Chris Booker, Victoria Farmer Margaret Johnston, and Megan Somerville for administrative assistance; Ashley Duncan and Michelle Harper from the Diabetes Laboratory of the Department of Human Nutrition, University of Otago, Southern Community Laboratory Dunedin and Diabetes New Zealand (www. diabetes.org.nz), who approved use of their diabetes dietary resources in the LOADD study.

Contributors: KJC and JIM conceived the study; contributed to the design, implementation, conduct, and monitoring of the study and analysis and interpretation of results; wrote most of the first draft; and were responsible for editing the manuscript. MK participated in the implementation and conduct of the study and contributed to the analysis, interpretation of the study, and editing the manuscript. SMW contributed to the design; did the analyses; and contributed to the interpretation of the study, writing the first draft, and editing the manuscript. AWC contributed to the design, implementation, conduct, and monitoring of the study; analysis and interpretation of results; and editing the manuscript. SMV participated in the implementation and conduct of the study and editing the manuscript. All authors approved the final draft of the manuscript. All authors had full access to all of the data. KJC and JIM are the guarantors.

Funding: This study was supported by grants from the Health Research Council of New Zealand (06/352) and the Southern Trust, New Zealand. The funders had no role in any aspect of the study.

Competing interests: All authors have completed the Unified Competing Interest form at http://www.icmje.org/coi_disclosure.pdf (available on request from the corresponding author) and declare: (1) No financial support for the submitted work from anyone other than their employer; (2) No financial relationships with commercial entities that might have an interest in the submitted work; (3) No spouses, partners, or children with relationships with commercial entities that might have an interest in the submitted work; (4) No non-financial interests that may be relevant to the submitted work.

Ethical approval: The Lower South Regional Ethics Committee approved this study (LRS/05/07/026), and participants gave written consent before the pre-randomisation clinical assessment.

Data sharing: No additional data available.

1 Mann II, De Leeuw I, Hermansen K, Karamanos B, Karlström B, Katsilambros N, et al. Evidence-based nutritional approaches to the treatment and prevention of diabetes mellitus. Nutr Metab Cardiovasc Dis 2004;14:373-94.

2 Ary DV, Toobert D, Wilson W, Glasgow RE. Patient perspective on factors contributing to nonadherence to diabetes regimen. Diabetes Care 1986;9:168-72.

3 Truswell AS, Thomas BJ, Brown AM. Survey of dietary policy and management in British diabetic clinics. BMJ 1975;4:7-11.

4 Krentz AJ, Bailey CJ. Oral antidiabetic agents: current role in type 2 diabetes mellitus. Drugs 2005;65:385-411.

5 Eliasson B, Eeg-Olofsson K, Cederholm J, Nilsson PM, Gudbjörnsdóttir S, for the Steering Committee of the Swedish National Diabetes Register (NDR). Antihyperglycaemic treatment of type 2 diabetes: results from a national diabetes register. Diabetes Metab 2007;33:269-76.

6 Coppell K, Anderson K, Williams S, Manning P, Mann J. Evaluation of diabetes care in the Otago region using a diabetes register, 19982003. Diabetes Res Clin Pract 2006;71:345-52.

7 Mann DM, Woodward M, Ye F, Krousel-Wood M, Muntner P. Trends in medication use among US adults with diabetes mellitus: glycemic control at the expense of controlling cardiovascular risk factors. Arch Intern Med 2009;169:1718-20.

8 Gudbjörnsdottir S, Cederholm J, Nilsson PM, Eliasson B, for the Steering Committee of the Swedish National Diabetes Register. The National Diabetes Register in Sweden: an implementation of the St Vincent Declaration for quality improvement in diabetes care. Diabetes Care 2003;26:1270-6.

9 Saydah SH, Fradkin J, Cowie CC. Poor control of risk factors for vascular disease among adults with previously diagnosed diabetes. JAMA 2004;291:335-42.

10 UK Prospective Diabetes Study (UKPDS) Group. Intensive bloodglucose control with sulphonylureas or insulin compared with conventional treatment and risk of complications in patients with type 2 diabetes (UKPDS 33). Lancet 1998;352:837-53.

11 Ruggiero L, Glasgow R, Dryfoos JM, Rossi JS, Prochaska JO, Orleans CT, et al. Diabetes self-management: self-reported recommendations and patterns in a large population. Diabetes Care 1997;20:568-76.

12 Rivellese AA, Boemi M, Cavalot F, Costagliola L, De Feo P, Miccoli R, et al. Dietary habits in type II diabetes mellitus: how is adherence to dietary recommendations? Eur J Clin Nutr 2008;62:660-4.

13 Gallwitz B, Häring HU. Future perspectives for insulinotropic agents in the treatment of type 2 diabetes-DPP-4 inhibitors and sulphonylureas. Diabetes Obes Metab 2010;12:1-11.

14 Holman RR, Farmer AJ, Davies MJ, Levy JC, Darbyshire JL, Keenan JF, et al, for the 4-T Study Group. Three-year efficacy of complex insulin regimens in type 2 diabetes. N Engl/ Med 2009;361:1736-47.

15 Simpson HC, Simpson RW, Lousley S, Carter RD, Geekie M, Hockaday TD, et al. A high carbohydrate leguminous fibre diet improves all aspects of diabetic control. Lancet 1981;1:1-5.

16 Chandalia M, Garg A, Lutjohann D, von Bergmann K, Grundy SM, Brinkley LJ. Beneficial effects of high dietary fiber intake in patients with type 2 diabetes mellitus. N Engl J Med 2000;342:1392-8.

17 New Zealand Guidelines Group. Management of type 2 diabetes. Ministry of Health and New Zealand Guidelines Group, 2003

18 National Institute for Health and Clinical Excellence. Type 2 diabetes: the management of type 2 diabetes. NICE, 2008.

19 Clinical Guidelines Task Force. Global guideline for type 2 diabetes. International Diabetes Federation, 2005.

20 Bauman A, McLean G, Hurdle D, Walker S, Boyd J, van Aalst I, et al. Evaluation of the national 'Push Play' campaign in New Zealand- 
creating population awareness of physical activity. $N$ Z Med J 2003;116:U535.

21 McAuley KA, Williams SM, Mann JI, Walker RJ, Lewis-Barned NJ, Temple LA, et al. Diagnosing insulin resistance in the general population. Diabetes Care 2001;24:460-4.

22 Coppell K, Manning P. Establishing a regional diabetes register and description of the registered population after one year. N Z Med J 2002;115:U146.

23 Wolf AM, Conaway MR, Crowther IQ, Hazen KY, L Nadler J, Oneida B, et al. Translating lifestyle intervention to practice in obese patients with type 2 diabetes: Improving Control with Activity and Nutrition (ICAN) study. Diabetes Care 2004;27:1570-6.

24 Clar C, Royle P, Waugh N. Adding pioglitazone to insulin containing regimens in type 2 diabetes: systematic review and meta-analysis. PLoS One 2009; 4:e6112.

25 Fonseca V, Schweizer A, Albrecht D, Baron MA, Chang I, Dejager S. Addition of vildagliptin to insulin improves glycaemic control in type 2 diabetes. Diabetologia 2007;50:1148-55.

26 Hollander P, Yu D, Chou HS. Low-dose rosiglitazone in patients with insulin-requiring type 2 diabetes. Arch Intern Med 2007;167:1284-90.

27 Stratton IM, Adler Al, Neil AW, Matthews DR, Manley SE, Cull CA, et al. Association of glycaemia with macrovascular and microvascular complications of type 2 diabetes (UKPDS 35): prospective observational study. BMJ 2000;321:405-12.

28 Perry TL, Mann Jl, Lewis-Barned NJ, Duncan AW, Waldron MA, Thompson C. Lifestyle intervention in people with insulin-dependen diabetes mellitus (IDDM). Eur J Clin Nutr 1997;51:757-63.

29 Aas AM, Bergstad I, Thorsby PM, Johannesen O, Solberg M, Birkeland KI. An intensified lifestyle intervention programme may be superior to insulin treatment in poorly controlled type 2 diabetic patients on oral hypoglycaemic agents: results of a feasibility study. Diabet Med 2005;22:316-22.

30 Goudswaard AN, Stolk RP, Zuithoff NP, de Valk HW, Rutten GE. Long term effects of self-management education for patients with type 2 diabetes taking maximal oral hypoglycaemic therapy: a randomized trial in primary care. Diabet Med 2004;21:491-6.

31 Look AHEAD Research Group, Pi-Sunyer X, Blackburn G, Brancati FL, Bray GA, Bright $R$, et al. Reduction in weight and cardiovascular disease risk factors in individuals with type 2 diabetes: one-year results of the look AHEAD trial. Diabetes Care 2007;30:1374-83.

32 Ogden CL, Carroll MD, Curtin LR, McDowell MA, Tabak Cl, Flegal KM Prevalence of overweight and obesity in the United States, 19992004. JAMA 2006;295:1549-55.

33 Ministry of Health. A portrait of health: key results of the 2006/07 New Zealand health survey. Ministry of Health, 2008.

34 World Cancer Research Fund/American Institute for Cancer Research. Food, nutrition, physical activity, and the prevention of cancer: $a$ global perspective. AICR, 2007.

35 Funnell MM, Anderson RM. Working toward the next generation of diabetes self-management education. Am J Prev Med 2002;22(suppl 4):S3-5.

36 American Diabetes Association, Bantle JP, Wylie-Rosett J, Albright AL, Apovian CM, Clark NG, et al. Nutrition recommendations and interventions for diabetes: a position statement of the American Diabetes Association. Diabetes Care 2008;31(suppl 1):S61-78.

37 Snoek F. Barriers to good glycaemic control: the patient's perspective. Int J Obes Relat Metab Disord 2000;24(suppl 3):S12-20.

Accepted: 19 May 2010 